\title{
Rare Disease Healthcare Experience: Qualitative Survey and Workshop Findings in the Context of UK Policy Development
}

Jennifer Jones

Genetic Alliance UK

Amy Simpson

Genetic Alliance UK

Nick Meade

Genetic Alliance UK

Daphnee Pushparajah

Alexion

David Newman

Alexion

Amy Hunter ( $\nabla$ amy.hunter@geneticalliance.org.uk )

Genetic Alliance UK https://orcid.org/0000-0001-5076-8761

\section{Research Article}

Keywords: survey, qualitative, patient experience, UK, UK Rare Diseases Framework

Posted Date: August 3rd, 2021

DOI: https://doi.org/10.21203/rs.3.rs-757576/v1

License: (1) This work is licensed under a Creative Commons Attribution 4.0 International License.

Read Full License 
Rare disease healthcare experience: qualitative survey and workshop findings in the context of UK

\section{policy development}

Jennifer Jones ${ }^{1}$, Amy Simpson ${ }^{1}$, Nick Meade ${ }^{1}$, Daphnee Pushparajah², David Newman², Amy Hunter ${ }^{1^{*}}$

1. Genetic Alliance UK. Creative Works, Blackhorse Lane, London. E17 6DS.

2. Alexion UK. Stockley Park, 3 Furzeground Way, Hayes, Uxbridge,. UB11 $1 E Z$.

*corresponding author

Abstract

Background: the UK Rare Diseases Framework is the latest policy initiative that aims to improve healthcare for rare diseases in the UK, with four priorities focussed on faster diagnosis, increasing awareness among healthcare professionals, better care coordination and improved access to specialist care and treatment. A survey of over 1,000 people living with rare diseases in the UK immediately prior to the publication of the Framework captured quantitative and qualitative data about their experiences. The qualitative analysis is presented here and compared with the content of the Framework.

Results: People living with a rare condition in the UK continue to have very mixed experiences of healthcare and our findings illustrate substantial continuing unmet needs that fall under each of the four priorities of the Framework. 
Conclusions: Comparing the findings with what is emphasised in the Framework suggests specific key changes to policy and practice which might be missed by action plans developed under the Framework. The overall provision in the UK for people living with rare conditions needs to be improved and regularly reviewed, to ensure they are not being unfairly excluded from appropriate diagnosis, treatment or support.

Keywords: survey; qualitative; patient experience; UK; UK Rare Diseases Framework

\section{Background}

The first UK Strategy for Rare Diseases was published in 2013 (1) and included 51 commitments. The key features included: personal care plans covering health and care services, access to information for patients, families and carers, better methods of identifying and preventing rare diseases, improving diagnosis, providing better education and training for health and social care professionals, and building on research to improve personalised approaches to healthcare.

Despite the existence of the Strategy, recent data indicate that living with a rare disease continues to present significant challenges to people in the UK. Genetic Alliance UK (in a partnership agreement with Alexion UK) completed an extensive survey (over 1,000 eligible responses) into the lived experiences of those who are affected by or cared for someone with a rare, genetic or undiagnosed condition $(2,3)$. Analysis from the quantitative elements of the survey showed that over one third rated their overall experience of care as either poor or very poor, around half of the respondents did not believe the quality of their care had improved over the last five years with a further 1 in 5 reporting care to have got worse. The diagnostic odyssey was still evident from the results with over half of patients (52\%) who had been diagnosed within the last five years having waited for over two years for their diagnosis, and $41 \%$ had waited for over five years. Half the respondents did not feel that their care was effectively coordinated, and just under half (48\%) stated that there was a specialist centre available for their condition but only around half of these (52\%) accessed the specialist centre. Two 
thirds of the respondents (64\%) believed that the system for making medicines available to patients is unfair on people who live with rare conditions. Both reports highlighted that those with more complex conditions (defined by the number of aspects of health affected) rated their experiences poorer compared to those who had less complex conditions. Fewer than $15 \%$ of respondents believed that the professionals they receive care from other than their 'regular' hospital clinicians (i.e. GPs, paramedics, emergency room staff and social care staff) have enough information about their conditions.

In January 2021 the UK government published a new UK Rare Diseases Framework to replace the 2013 strategy (4). Within this document four priority areas are outlined: helping patients get a final diagnosis faster; increasing awareness of rare diseases among healthcare professionals; better coordination of care; and improving access to specialist care, treatments and drugs. The selection of the priority areas in the Framework was partly based on a 2019 survey called the "National Conversation on Rare Disease" designed to identify the main challenges for those living with, caring for or working with rare diseases.

There is a commitment from the four nations of the UK to develop action plans to deliver the aims of the new Framework. It is clear from Genetic Alliance UK's recent survey $(2,3)$ that currently not all healthcare needs of those with rare conditions are being met. For the new UK Framework to be successful in addressing these needs the action plans need to cover all the challenges which are faced by those in the rare condition community. The aim of this study was to carry out a systematic and detailed qualitative analysis of the text responses to open-ended questions in the Genetic Alliance UK survey to highlight elements which may be missing from the Framework but which could be incorporated into the action plans. 


\section{Methods}

\section{Survey instrument}

An online survey of 102 questions was distributed in late June to early August 2020; the survey was hosted using the SurveyMonkey platform. The questions were based on previous surveys undertaken by Genetic Alliance UK $(5,6)$, other patient experience surveys (such as the Cancer Patient Experience Survey (7)), other relevant studies (such as the CONCORD study focussing on care coordination (8)) and the anticipated focus of the new UK Rare Diseases Framework (4). The survey instrument [see Additional file 1] used a mixture of closeended questions with pre-defined response categories and open-ended questions where respondents could supply qualitative information in open-ended text boxes. Only data from the qualitative questions are reported in this paper; results from the quantitative questions have been published elsewhere $(2,3)$.

Respondents were asked to consent to taking part in the survey and then separately to the use of their quotes in future publications. Respondents were asked for details about the rare / undiagnosed condition and some questions were filtered in order to be appropriate for those who had not yet received a diagnosis. Question areas focussed on the search for a diagnosis; information, awareness and the patient voice; coordination of care; access to specialist care and treatments; experiences related to research; the use of technology; overall experiences of care; and experiences due to Covid-19.

Six individuals were invited to pilot the survey before general release. Five took up the invitation: three parents of affected individuals (two with school-age children and one whose child is now an adult), one affected adult and one social scientist. They piloted the survey in their own time, responded to specific questions asked by the authors, and provided further comments. Feedback was sent by email in four cases and by phone in one. The survey was refined in line with the pilot feedback.

\section{Survey sampling}

The survey was open to anyone aged 18 or over who considered that they, or the person they care for, has a rare, genetic or undiagnosed condition and were living in the UK. Currently, no complete sample list exists of all people who consider they have a rare, genetic or undiagnosed condition so it is not possible to create a random 
sample; therefore, a convenience snowball sample was the most appropriate sampling approach to take. No response rates are available as the link to the survey was sent via multiple overlapping distribution routes as it was shared widely across Genetic Alliance UK, Rare Disease UK and SWAN UK's networks and member organisations. Due to the nature of this survey, where participants were recruited independently of the NHS, this work is exempt from the UK National Research Ethics Service and Health Research Authority regulations.

\section{Data analysis}

There were 1,433 eligible responses. Qualitative data was imported into NVivo Release 1.2 (QSR International). In order to create a coding frame of top-level codes and sub-codes all the quotes were read through alongside the open-ended questions used in the survey and the anticipated elements of the UK Rare Diseases Framework. The coding frame was then discussed with other members of the research team; top-level codes included the lived experiences outside of healthcare, the diagnostic journey, interactions with the healthcare service, healthcare professionals' interactions with each other and those with rare conditions, the feelings of those with rare conditions in terms of challenges and issues, information and support needs, care coordination, medicines and treatment, research, technology and issues specific to Covid-19. All of the approximately 6,000 comments provided in the survey were coded by one researcher $(\mathrm{JJ})$ who had ongoing discussions regarding coding with another researcher (AH), who also checked a subset of codes ( $10 \%)$. Coding was flexible so that as new codes were identified they were added to the coding frame. Data from those not consenting to having their quotes used were included to inform the analysis but their individual quotes have not been selected to be presented in this paper. The text of the UK Rare Diseases Framework was compared to the findings from the survey to establish where there were elements missing.

\section{Workshops}

Following completion of the survey and some initial quantitative analysis, two online workshops took place with 11 respondents who had completed the survey and indicated that they would be interested in taking part in workshops. The workshop participants came from all four UK nations and represented both carers and 
people with a rare or undiagnosed condition. The survey findings were presented and then discussed with the participants. The outputs from the workshops were included in the analysis for this paper. 


\section{$\underline{\text { Results }}$}

\section{Sample characteristics}

There were 1,433 eligible respondents included in the qualitative analysis of the survey. Around 300 different rare / genetic conditions are represented in the survey, with around 200 only being mentioned by one respondent while 17 conditions were mentioned by nine or more respondents. About $10 \%$ of respondents mentioned living with more than one rare condition. People living with a condition made up $79 \%$ of the respondents while the other $21 \%$ were carers. There was limited ethnic diversity amongst the respondents with $96 \%$ identifying as having a white background. The survey was answered more often by women $(1,146-80 \%)$ than men (207 - 14\%). See Table 1 for a detailed breakdown of the demographics of the respondents and the people cared for if a carer completed the survey. 
Table 1 Demographics of the respondents answering the survey and those they care for (if appropriate)

\begin{tabular}{|c|c|c|c|c|}
\hline & & $\begin{array}{l}\text { Person with condition } \\
\text { answering the survey }\end{array}$ & $\begin{array}{l}\text { Carer answering } \\
\text { the survey }\end{array}$ & $\begin{array}{l}\text { Carer describing } \\
\text { person they care for }\end{array}$ \\
\hline Sex & $\begin{array}{r}\text { Male } \\
\text { Female } \\
\text { Other } \\
\text { Prefer not to say } \\
\text { Missing }\end{array}$ & $\begin{array}{c}179(15 \%) \\
906(80 \%) \\
4(0.4 \%) \\
4(0.4 \%) \\
41(4 \%)\end{array}$ & $\begin{array}{c}28(9 \%) \\
240(80 \%) \\
0 \\
2(0.7 \%) \\
29(10 \%)\end{array}$ & $\begin{array}{l}144(48 \%) \\
123(41 \%) \\
1(0.3 \%) \\
1(0.3 \%) \\
30(10 \%)\end{array}$ \\
\hline Age & $\begin{array}{r}\text { Under } 18 \\
18-24 \\
25-34 \\
35-44 \\
45-54 \\
55-64 \\
65-74 \\
75+ \\
\text { Prefer not to say } \\
\text { Missing }\end{array}$ & $\begin{array}{c}\text { NA } \\
69(6 \%) \\
168(15 \%) \\
205(18 \%) \\
271(24 \%) \\
224(20 \%) \\
130(12 \%) \\
25(2 \%) \\
2(0.2 \%) \\
40(4 \%)\end{array}$ & $\begin{array}{c}\text { NA } \\
3(1 \%) \\
37(12 \%) \\
108(36 \%) \\
78(26 \%) \\
31(10 \%) \\
11(4 \%) \\
1(0.3 \%) \\
1(0.3 \%) \\
29(10 \%)\end{array}$ & $\begin{array}{c}204(68 \%) \\
25(8 \%) \\
17(6 \%) \\
8(3 \%) \\
1(0.3 \%) \\
4(1 \%) \\
8(3 \%) \\
2(1 \%) \\
0 \\
30(10 \%)\end{array}$ \\
\hline Region & $\begin{array}{r}\text { East of England } \\
\text { East Midlands } \\
\text { London } \\
\text { North East \& Cumbria } \\
\text { Northern Ireland } \\
\text { North West of England } \\
\text { Scotland } \\
\text { South East of England } \\
\text { South West of England } \\
\text { Wales } \\
\text { West Midlands } \\
\text { Yorkshire } \\
\text { Prefer not to say } \\
\text { Missing }\end{array}$ & $\begin{array}{l}105(9 \%) \\
69(6 \%) \\
92(8 \%) \\
46(4 \%) \\
14(1 \%) \\
119(11 \%) \\
94(8 \%) \\
209(18 \%) \\
119(11 \%) \\
76(7 \%) \\
61(5 \%) \\
84(7 \%) \\
8(0.7 \%) \\
38(3 \%)\end{array}$ & $\begin{array}{c}13(4 \%) \\
26(9 \%) \\
17(6 \%) \\
10(3 \%) \\
8(3 \%) \\
32(11 \%) \\
27(9 \%) \\
58(19 \%) \\
26(9 \%) \\
17(6 \%) \\
22(7 \%) \\
14(5 \%) \\
0 \\
29(10 \%)\end{array}$ & $\begin{array}{l}13(4 \%) \\
25(8 \%) \\
17(6 \%) \\
9(3 \%) \\
8(3 \%) \\
32(11 \%) \\
27(9 \%) \\
56(19 \%) \\
29(10 \%) \\
17(6 \%) \\
22(7 \%) \\
14(5 \%) \\
0 \\
30(10 \%)\end{array}$ \\
\hline
\end{tabular}




\section{Survey Findings}

The structure of the analysis was based on the 2021 UK Rare Diseases Framework (4) priorities:

1. "helping patients get a final diagnosis faster"

2. "increasing awareness of rare diseases among healthcare professionals"

3. "better coordination of care"

4. "improving access to specialist care, treatments and drugs"

The Framework's "underpinning themes” (patient voice; national and international collaboration; pioneering research; digital, data and technology; wider policy alignment) were not reflected in the qualitative data. An additional theme of the impact of the Covid-19 pandemic is presented.

Priority one: helping patients get a final diagnosis faster

The sample was diverse in terms of the length of time diagnosis had taken (less than 3 months to more than 20 years), and about $10 \%$ remained undiagnosed.

\section{Patient pathways - holistic body approach}

For many the diagnostic journey involved referral from primary care, followed by being discharged from a specialist clinic and returning to primary care to be referred back into a different part of secondary care. The system which people have to negotiate to achieve a diagnosis can be seen as daunting. Respondents described not being 'looked at' holistically by anyone- which was felt to contribute to delays in diagnosis.

"the NHS did not look at the whole picture and only tried to address individual symptoms. A diagnosis required all the symptoms to be put together in the same picture"

\section{Importance of getting a diagnosis}

For many respondents who did not have a diagnosis, there continued to be the desire to find one but they did not necessarily feel supported in doing this by the healthcare system. 


\section{Uncertainty of diagnosis (experiencing misdiagnoses)}

Along the journey to a diagnosis some respondents outlined how they had received misdiagnoses. This was distressing for some people who did not feel the diagnosis matched what they perceived their condition to be or in retrospect realised that they had received inappropriate treatment or care. Some respondents indicated that their misdiagnosis was sometimes due to physical symptoms being treated as psychological symptoms. Others mentioned they have been labelled as 'drug-seekers' or 'nuisances'.

"A lot of my symptoms were dismissively blamed on anxiety rather than investigated properly. I have anxiety because of symptoms, not the other way around."

\section{Enablers / barriers to speeding up diagnosis}

Respondents indicated ways in which they tried to increase the speed of diagnosis including paying to go private, doing their own research and being 'lucky' that another family member already had a diagnosis. Issues which people highlighted were; poor communication between doctors, being passed between specialties, the system being slow in terms of being referred and receiving appointments, lost medical records and results, and general lack of resources.

"I was lucky - based on my family history, my consultant tested me quite early after onset of symptoms."

"I wasn't treated as an individual, but as a nuisance. This has affected my mental health seriously." 


\section{Genetic testing}

Not all those with rare conditions have had genetic tests performed. For some this was because testing was not available when they initially searched for a diagnosis, for others a genetic test was not appropriate as there is not a genetic basis for their condition whilst others have been unable to secure a genetic test. Some people who were diagnosed years ago have had their diagnosis confirmed by a genetic test once they became available (so the genetic test was not done at the time of diagnosis). More recently, when some respondents talked about genetic testing it was describing the struggle experienced to get tests or test results. For some genetic testing has led to a diagnosis and ended their search for a diagnosis.

"The search was led by me but once we found the right doctor they worked very hard to find an answer. Things changed as genetic testing improved."

"Every appointment seems to end in 'hopefully we will get some results from the 100k genome project soon so we will wait for that' but 3 years on we still have no results and are no further on with a working diagnosis."

\section{Priority two: increasing awareness of rare diseases among healthcare professionals}

Respondents meet many healthcare professionals during their journey to find a diagnosis and then receiving ongoing care. This can be a very positive experience, however for some respondents the relationship with some of the people they meet can be challenging.

\section{Challenging interactions with healthcare professionals}

Challenges include not being listened to, being dismissed, not being treated holistically, a perceived lack of knowledge from the healthcare professionals with some admitting that they don't know what to do. The feelings of dismissal often arose from physical symptoms being treated as mental health problems. 
Respondents said that feeling not heard or believed by doctors subsequently led to them losing trust and confidence in the NHS generally and some doctors specifically.

"Lack trust of NHS, GPS, doctors generally - felt they were laughing at my weird collection of symptoms and thought me a hypochondriac. My mental health massively deteriorated following mis diagnosis."

Respondents mentioned the lack of knowledge of healthcare professionals especially outside of the hospital system, and indicated that there may be further issues if they had an unusual form of the rare condition but their case was treated as 'textbook'. Respondents commented that within primary care there was generally very little knowledge about their condition and they often felt unsupported with the impression that the GP's interest was limited; there were however, exceptions to this.

"GPs haven't the slightest clue luckily I have 1 GP in my whole surgery who knows what it is and is very knowledgeable so I always request him"

"many people have not heard of ataxia. My GP surgery gives me no support and the only consultation is once a year with neurology"

\section{'Patient experts' - knowledge of those with / caring for those with rare conditions}

Respondents in the survey often described how they have had to acquire knowledge about their condition and in the process have become the expert. There was a lot of pressure on respondents to find out information with some going to great lengths to learn as much as they could, including reading academic journals, attending conferences and making direct contact with experts in the field from around the world. Some respondents have described how when they go to see someone who is not an expert they may be in a situation where they know more than the consultant; this imbalance of knowledge sometimes led to issues when interacting with healthcare professionals who respondents implied were sometimes uncomfortable with this situation. Another 
situation described by respondents was when the healthcare professional admits they know nothing about the condition but then proceed to tell the respondent what they are going to do, ignoring the patient's expertise.

Listen to the patient - they are often the ones who have had the time \& drive to do the research in their condition.

Some respondents felt put under pressure to make treatment decisions which they felt unqualified to do.

"We have often been put in impossible positions where two clinicians disagree on care and then parents are asked to decide which way forward."

Respondents acknowledged that healthcare professionals could not know about all conditions as there were so many rare conditions but some felt that the healthcare professionals should try to learn about them if they have an affected patient.

"Generalist practitioners cannot know about all conditions but they do need to know where they can access information when presented with a patient with a rare condition."

\section{Feeling 'unsafe' in the system}

Respondents indicated that they are concerned when they are dealing with healthcare professionals who are not aware of their condition as they feel their health is potentially at risk if an inappropriate treatment or medication is administered. To feel more secure some described having alert cards or wearing medical alert jewellery or that they took 'evidence' with them such as a diagnostic letter or information about their condition which they could use in health situations where healthcare professionals did not have access to their notes.

"I rarely feel safe with a care provider who is not aware of my condition, or who is making medical or medication decisions that are not appropriate for someone who has said condition." 

conditions and symptoms"

\section{Positive experiences with healthcare professionals}

Respondents reported positive experiences regarding their interactions with healthcare professionals, citing examples when they have been asked about their condition in order for healthcare professionals to further their knowledge. Some respondents highlighted good relationships with their doctors or felt that awareness amongst healthcare professionals had improved which had led to better care. Improved communication and forming good relationships with their healthcare providers had also led to improvements in care. Some described themselves as fortunate that they had always had good care across multiple healthcare settings.

"This condition is rarely known by most professionals, however the team that have been dealing with me have really tried to understand and get their heads round the complete picture of my diagnosis to enable them to treat me adequately. I am very happy with them."

"After years of suboptimal treatment in the NHS, I found a GP and a neurologist I can trust and who trust me."

\section{Priority three: better coordination of care}

Those with rare conditions where multiple aspects of health are affected are likely to be seeing different specialists within different departments and often across different hospitals.

\section{Communication between healthcare professionals / disjointed care}

Poor communication between healthcare professionals in different settings, including lack of sharing of medical records, and a complete lack of coordination of care, were reported as contributing to poor care 
overall. Poor coordination was reported as putting a burden onto patients or their carers because they have to constantly repeat themselves and provide medical information to healthcare professionals. As with the path to diagnosis, respondents reported that they were sometimes treated as individual symptoms by individual clinicians rather than being looked at holistically as they accessed care within the system.

"Each different clinic has been entirely independent of the others. None of the plans has taken the other clinics into consideration."

Within the healthcare system respondents stated that there was a lack of ownership of them or their condition.

"When an individual has multiple rare conditions they are all handled independently with professionals fighting over which is the worst condition as that specialist becomes lead and the others can abdicate responsibility"

For those who had transitioned between child and adult services there was a sense that they were having to 'start all over' again. There was also potential confusion when different clinics transitioned children to adult services at different ages.

"No coordinated transition from child to adult care. Had to start all over."

\section{Experience of care coordination}

Respondents comments indicate how difficult it is to coordinate their own care or that of someone they look after. They talked about how exhausting it was and that they were unsure what they were doing. Respondents stated that they often did not have a choice over who coordinated their care, and sometimes the carer / person with the condition had to take over the role even if it had been assigned to someone else.

"There is no coordination of my daughters care by anyone other than myself and her and frankly we are floundering around in the dark" 
"Although in a residential care home that is supposed to coordinate all needs, this is having to be done remotely by me as a parent."

A diagnosis was sometimes reported as improving care coordination. Respondents described the positive aspects of having their care coordinated, and this was apparent for different types of coordinator.

"My specialist nurse tells me exactly where I need to go for appointments and when, what I need and what I need to do. I'm blessed and grateful for such good care."

"Without a diagnosis, with clinical evidence, coordination of care is virtually impossible. Once a diagnosis is reached charitable organisations offer valuable support."

\section{Who they would like to coordinate their care}

For some respondents there was a sense that they were on 'opposing sides' to the medical team and they would have preferred a joint approach to coordination. Some felt that a care coordinator (other than themselves) would 'ensure nothing was missed'.

"I would really appreciate someone with knowledge of my son's condition overseeing his care to ensure nothing is missed."

"A personal care Coordinator who is on my side (it sometimes feels like I'm on opposing sides with the medical team) to sort things out instead of me battling away just to get basics, would be great."

\section{Priority four: Access to specialist care and treatments}

The rarity of patients requiring a specialised service or treatment, and the concomitant rarity of knowledgeable healthcare professionals, puts additional barriers in front of access to appropriate services and treatments.

\section{Accessing specialist care}


Respondents often said they were happy to travel long distances to access specialist care if it was not available locally. The reported benefits of seeing doctors who are experts in their rare condition included not having to repeatedly explain it.

"I don't have to explain everything over and over again"

Respondents spoke very positively about specialist centres if they were able to access them. They valued being able to see lots of different healthcare professionals and others in one trip. Respondents also liked being listened to; the centres being responsive to their needs; and being treated holistically.

"At annual review, I see a number of health care professionals ie doctor, physiotherapist and have all relevant tests eg ecg, breathing tests within the one appointment which is very well organised"

Conversely respondents described the emotional and physical toll of feeling let down by the NHS and doctors; there seemed to be a constant 'battle' or 'fight' to get anything done or be heard. Some described the 'unfairness' of the system when others received care they did not.

"It feels as though you're shouting "help" but no words are coming out... We've been let down by not just one hospital but all of them and the over 20 doctors we've seen."

"It feels like there's a fight for everything. It's hard seeing people in different parts of the country being offered services we have to fight for."

Respondents described how they have difficulties accessing appointments and referrals, with some saying they receive no care at all, despite requesting it. Some respondents appear to avoid interaction with the health service.

"I was fobbed off by my GP and hospital specialists. I'm still reluctant to visit GP with ongoing symptoms." 
Some respondents found that once they had been diagnosed their interactions with the health system reduced or ceased altogether. Some responses indicated that geography or funding impacted on the care they received. "I feel diagnosed and abandoned. very difficult to get reviews to manage the condition and medications"

"I have managed to access more specialised care. In this time I have also moved from the North East which may be an influence."

"I frequently ask for more help/information about my condition but get told there's no money for rare conditions as there's not enough uptake to justify it. I am here, I am justification, I am worthy of help."

\section{Barriers to accessing specialist care / centres}

Some respondents said they had difficulty accessing specialist centres describing long waiting lists and having to travel long distances to access them. For some, even if the care was within the same country, the distance of travel was prohibitive and they therefore did not attend; others found difficulties in crossing borders to receive care.

"I've discovered shared care is available to patients living in South of Ireland with London hospital I requested this and never received it... Belfast trust do not allow patients to travel outside NI if treatment will cost them." 
Sometimes paying privately seemed the only way to be able to see expert doctors. Respondents also highlighted difficulties getting referrals from primary care or secondary care. Some specialist centres were only concerned with diagnosis and not ongoing care.

"Specialist care and knowledge has only been open to us having gone private. Immunology is severely underfunded in the UK, not enough expertise is available."

The two national centres are more concerned with diagnosis than ongoing supervision and treatment advice. Certainly not supervision of care over the years

\section{Medications / treatments - availability, accessibility and suitability}

For some conditions there are no treatments or medications available or they are difficult to access. Some respondents are not confident they are offered the best medication for their condition. Funding was also an issue for individual respondents trying to access medications. Respondents described the allocation of funding for rare diseases as 'unfair' and some described the stress of having to battle for medications or treatments.

"cheapest, least effective options offered"

"There are therapies available, but I do not qualify for them at the moment. I do not know how decisions about access to therapies are made, but of course the NHS is underfunded in all areas."

"The hardest part has been accessing Mental Health support." 


\section{Impact of the pandemic}

Respondents talked about the increased use of remote consultations and their pros and cons, and about their general care in the pandemic. Some respondents said that the poor care and isolation they experienced before the pandemic meant that nothing had changed. Some respondents were critical of how the government had responded to the pandemic and how they had been treated as a group.

"I find over phone it's a lot easier for the patient to be interrupted or cut off when they are trying to explain something"

"Phone calls with specialist nurse is useful so I don't have to travel."

"We have been abandoned so nothing has changed as we weren't receiving anything before" 


\section{Discussion}

Although the survey was carried out during the pandemic year of 2020, the key issues it explored are long term and the findings are consistent with previous surveys in the UK and worldwide. (9-12). Respondents reported challenges concerning their interactions with the healthcare system that speak to the four priorities of the new UK Rare Diseases Framework (4); getting a diagnosis, the impact of the lack of knowledge amongst healthcare professionals, how they access care and how this is coordinated, and how they access drugs, treatment and specialised care.

The impact of diagnostic delay is well documented $(13,14)$ and our respondents highlighted how important it was to receive a diagnosis in order to get further medical and other types of support. Frustrations and challenges felt by parents waiting for diagnoses for their children (15) were echoed by our respondents in terms of not being listened to or believed by healthcare professionals.

Seeing someone knowledgeable about their condition was of great value to our respondents. Conversely, lack of awareness amongst healthcare professionals was mentioned by respondents in many contexts such as searching for a diagnosis, continuity of care and emergency care situations. A lack of knowledge among primary care doctors was particularly highlighted, as they have a vital role not only in arranging referrals to seek diagnosis but also being the main point of contact for many for their ongoing care. The challenge for primary care doctors in diagnosing ('recognising the zebras among the horses') (16) and caring for those with rare conditions has been previously recognised (17). It is concerning that some respondents described feeling unsafe or fearful when they were in a healthcare setting with professionals who lacked knowledge of their conditions. Mistrust in doctors and the healthcare system, feelings of insecurity, fear and anger among those with rare conditions has been reported before (18-20). It is important that those with rare conditions and healthcare professionals have access to information so that a partnership can be formed between them. When that happens, trust and direct clinical benefits such as earlier diagnosis can follow (21). 
In line with previous research, our respondents outlined how challenging it could be to coordinate care (22-25). Recent research highlights the importance of information sharing and communication between different parts of the health service in order to achieve smooth coordination of care (26), and of the importance of integrating mental health care into rare disease services (27). The idea of an 'holistic perspective' from healthcare professionals mirrors the proposal for better integrated systems and was often commented on by our respondents. Both of these are mitigated against by medical training taking a traditional block curriculum approach where topics are taught relating to one bodily system at a time - this is then echoed in hospitals where specialisms are not encouraged to integrate. Some respondents felt there was no 'ownership' of their case within the healthcare system, leading to a 'fight' for care and for some to seek help in the private sector if they could afford it. For those who had experienced transition between child and adult services there was a sense of having to start again.

Many respondents had no specialist centres for their condition, but those that did had generally favourable experiences as has been reported elsewhere (28). Some could not access specialist centres if there were barriers such as distance, long waiting lists or if the centre offered only diagnosis and not ongoing care. Some respondents described feeling abandoned if there was no treatment or drugs available to them.

The new UK Rare Diseases Framework (4) aims to address many of the issues that our data highlight as important for individuals affected by rare conditions. However, our findings also point to necessary changes that are not within the scope of the Framework, or that the authors consider will not naturally flow from it and require further emphasis. For the Framework to be successful these changes need to be taken into account as the four national plans are developed. See Table 2.

\section{[location for Table 2]}

Given the number of rare conditions and lack of registry data for them, it is not possible to survey a fully representative sample of rare diseases in the UK. By using social media and patient group networks the survey reached a diverse set of individuals in terms of complexity of condition, geographic region, and respondents' 
stage of their diagnostic/post-diagnosis journey. There remains a skew in the study sample towards respondents who are white, female and who are themselves affected (rather than being carers, for example of children). Another limitation is the unknown impact of running the survey during the first year of the Covid-19 pandemic, although the qualitative analysis presented here echoes themes uncovered by past research illustrating the key conclusion that many unmet needs remain.

\section{Conclusions}

People living with a rare condition in the UK continue to experience unmet needs under all the priorities of the latest policy initiative, the UK Rare Diseases Framework. However, there are gaps in the content of the Framework. As the four constituent nations of the UK develop their action plans in order to implement the Framework, emphasis should be placed on the changes to policy and practice that are proposed from our findings. As many of those with rare conditions currently use self-funding both to find a diagnosis and to receive ongoing care, the overall provision in the UK for people living with rare conditions needs to be regularly reviewed, to ensure they are not being unfairly excluded from appropriate diagnosis, treatment or support. 


\section{$\underline{\text { Declarations }}$}

Ethics. Due to the nature of this survey, where participants were recruited independently of the NHS, this work is exempt from the UK National Research Ethics Service and Health Research Authority regulations.

Consent for publication. Participants were asked to give specific consent for the use of anonymised quotes from their responses in publications.

Availability of data and materials. The datasets generated and/or analysed during the current study are not publicly available due to the presence of identifying information, but anonymised subsets of the data are available from the corresponding author on reasonable request.

Competing interests. The research was funded by Alexion through a partnership agreement. Alexion are a global biopharmaceutical company focussing on developing therapies for those living with rare conditions. DP and DN are employees of Alexion.

Funding. This research was funded by Alexion through a partnership agreement. Alexion are a global biopharmaceutical company focussing on developing therapies for those living with rare conditions.

Authors' contributions. The survey was developed by AS, AH and NM with input from DP and DN, and analysed by JJ with oversight from AH. The workshops were organised and run by JJ and AH. The manuscript was drafted by JJ and AH with input from AS, NM, DP and DN.

Acknowledgements. We would like to thank all the participants, the patient groups and individuals who helped distribute the survey and the workshop invitation, and Isabel Rundle for supporting the workshops. 


\section{References}

1. Department of Health. The UK Strategy for Rare Diseases. In: Department of Health, editor. 2013.

2. Genetic Alliance UK. Rare Experience 2020 The lived experiences of people affected by genetic, rare and undiagnosed conditions. Genetic Alliance UK; 2020.

3. Alexion UK. Reforming Rare Diseases. Alexion UK; 2020.

4. Department of Health and Social Care. The UK Rare Diseases Framework. 2021.

5. Limb L, Nutt S, Sen A. Experience of Rare Diseases: An Insight from Patients and Families. London, UK: Rare Disease UK; 2010.

6. Muir E. The Rare Reality - an insight into the patient and family experience of rare disease. London, UK: Rare Disease UK; 2016.

7. NHS England. Cancer Patient Experience Survey [Available from: https://www.england.nhs.uk/statistics/statistical-work-areas/cancer-patient-experience-survey/ ]. 8. UCL. CONCORD: CoOrdiNated Care of Rare Diseases 2018 [Available from: https://www.ucl.ac.uk/epidemiology-health-care/research/applied-health-research/research/healthcare-organisation-and-management-group/concord ]

9. Molster C, Urwin D, Di Pietro L, Fookes M, Petrie D, van der Laan S, et al. Survey of healthcare experiences of Australian adults living with rare diseases. Orphanet J Rare Dis. 2016;11:12.

10. Courbier S, Berjonneau E. Juggling care and daily life: the balancing act of the rare disease community. Paris, France: EURORDIS; 2017.

11. Kole A, Faurisson F. Rare Diseases Social Epidemiology: Analysis of Inequalities. Rare Diseases Epidemiology. Advances in Experimental Medicine and Biology. 686. Berlin: Springer-Verlag Berlin; 2010. p. 223-50. 
12. von der Lippe C, Diesen PS, Feragen KB. Living with a rare disorder: a systematic review of the qualitative literature. Mol Genet Genomic Med. 2017;5(6):758-73.

13. Evans WRH. Dare to think rare: diagnostic delay and rare diseases. Br J Gen Pract. 2018;68(670):224.

14. de Vries E, Fransen L, van den Aker M, Meijboom BR. Preventing gatekeeping delays in the diagnosis of rare diseases. Br J Gen Pract. 2018;68(668):145-6.

15. Lewis C, Skirton H, Jones R. Living Without a Diagnosis: The Parental Experience. Genet Test Mol Biomark. 2010;14(6):807-15.

16. Evans WRH, Rafi I. Rare diseases in general practice: recognising the zebras among the horses. Br J Gen Pract. 2016;66(652):550-1.

17. Atherton A. Primary care for patients with rare chronic illnesses. European Journal of General Practice. 1997;3(2):58-61.

18. Barlow JH, Stapley J, Ellard DR. Living with haemophilia and von Willebrand's: A descriptive qualitative study. Patient Educ Couns. 2007;68(3):235-42.

19. Grut L, Kvam MH. Facing ignorance: people with rare disorders and their experiences with public health and welfare services. Scandinavian Journal of Disability Research, . 2013;15(1),:pp.2032

20. von der Lippe C, Frich JC, Harris A, Solbraekke KN. Experiences of Being Heterozygous for Fabry Disease: a Qualitative Study. J Genet Couns. 2016;25(5):1085-92.

21. Davlin AS, Clarkin CM, Kalish JM. Beckwith-Wiedemann Syndrome: Partnership in the Diagnostic Journey of a Rare Disorder. Pediatrics. 2018;141(3):4.

22. Rare Disease UK. Rare Disease Care Coordination: Delivering Value, Improving Services. London, UK: Genetic Alliance UK; 2013. 
23. Van Groenendael S, Giacovazzi L, Davison F, Holtkemper O, Huang ZX, Wang QY, et al. High quality, patient centred and coordinated care for Alstrom syndrome: a model of care for an ultra-rare disease. Orphanet J Rare Dis. 2015;10.

24. Goodwin N, Sonola L, Thiel V, Kodner DL. Co-ordinated care for people with complex chronic conditions Key lessons and markers for success. London, UK: The King's Fund; 2013.

25. Simpson A, Bloom L, Fulop NJ, Hudson E, Leeson-Beevers K, Morris S, et al. How are patients with rare diseases and their carers in the UK impacted by the way care is coordinated? An exploratory qualitative interview study. Orphanet J Rare Dis. 2021;16(1):12.

26. Walton H. Developing a taxonomy of care coordination for rare conditions 2021 [Available from: https://www.youtube.com/watch?v=oRg-BsF5px0 ]

27. Spencer-Tansley R, Hunter A. Mental Health and rare diseases: mixed method study and policy recommendations. Orphanet J Rare Dis. 2018;13(S2 Article number 167. 9th European Conference on Rare Disease and Orphan Products, ECRD 10-12 May 2018, Vienna, Austria).

28. Garrino L, Picco E, Finiguerra I, Rossi D, Simone P, Roccatello D. Living With and Treating Rare Diseases: Experiences of Patients and Professional Health Care Providers. Qual Health Res. 2015;25(5):636-51. 
Table 2. Additional changes required to meet the strategic aims of the UK Rare Diseases Framework

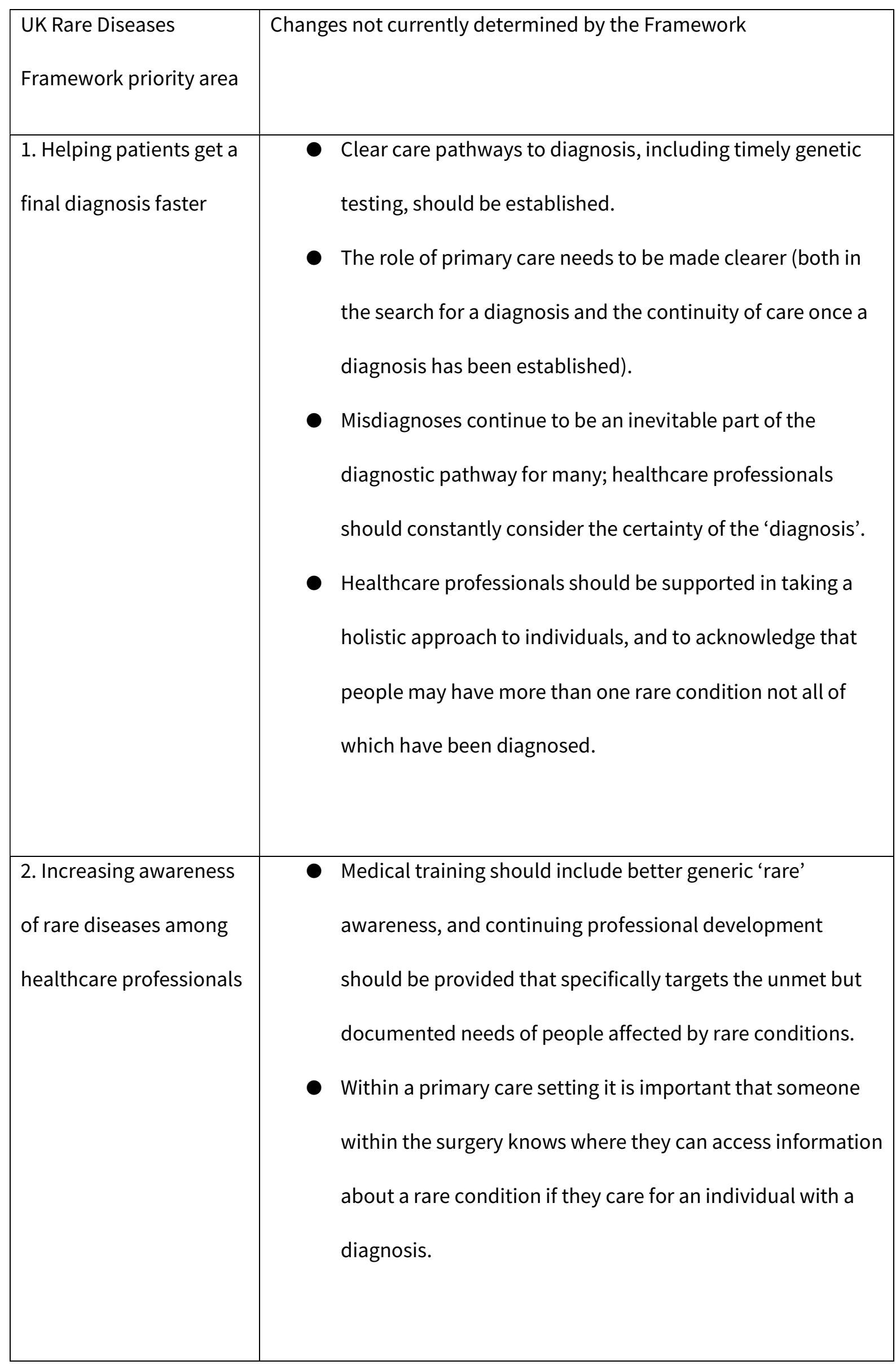




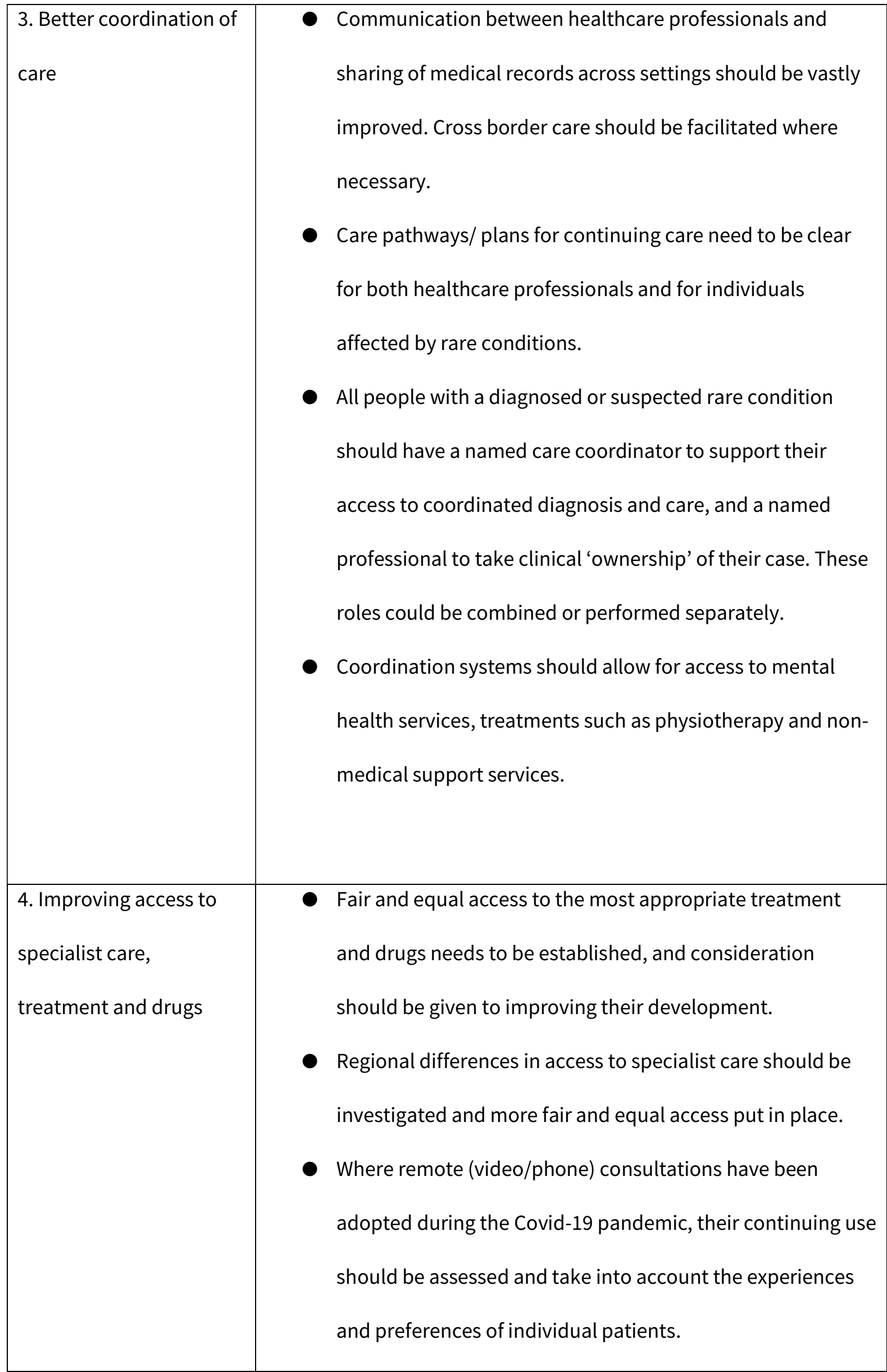




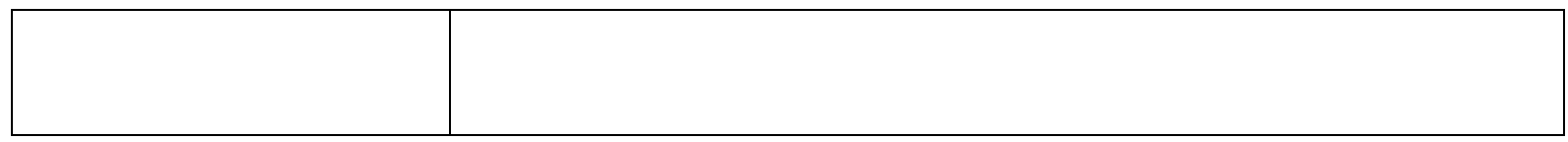

\section{Additional material}

One file of additional material is submitted with this manuscript:

File name: Additional file 1_survey instrument

File format: Pdf

Data is: the Genetic Alliance UK patient experience survey 2020, which is the online questionnaire used to collect the views and experiences about healthcare of people affected by rare conditions and which generated the qualitative data presented in this paper. 


\section{Supplementary Files}

This is a list of supplementary files associated with this preprint. Click to download.

- Additionalfile1surveyinstrument.pdf 